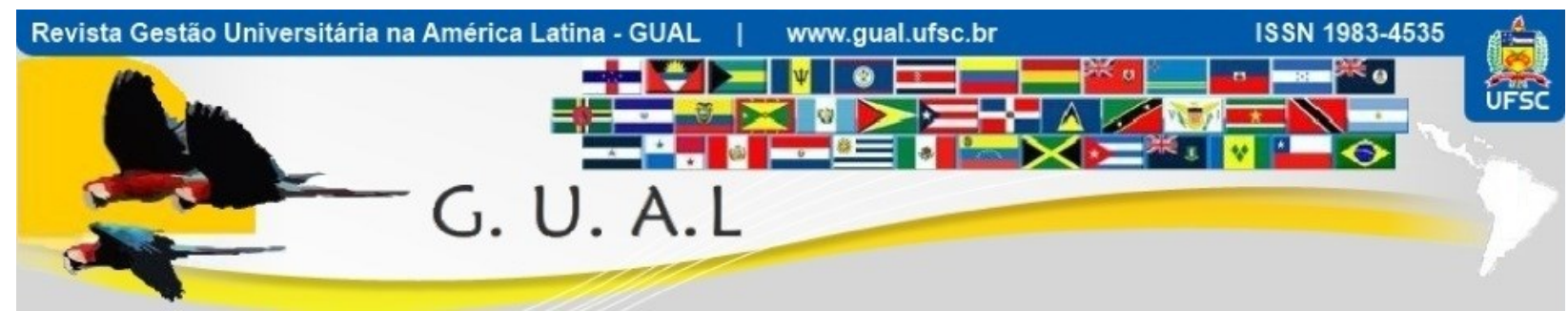

DOI: http://dx.doi.org/10.5007/1983-4535.2020v13n1p115

\title{
MÍDIAS SOCIAIS, UMA QUESTÃO A SER ENFRENTADA: A PERCEPÇÃO DOS ALUNOS SOBRE AS ABORDAGENS METODOLÓGICAS E OS PRINCÍPIOS DO CONECTIVISMO
}

\section{SOCIAL MEDIA, A QUESTION TO BE FACED: THE PERCEPTION OF STUDENTS ON METHODOLOGICAL APPROACHES AND THE PRINCIPLES OF CONNECTIVISM}

Samuel Lyncon Leandro de Lima, Mestre http://orcid.org/0000-0003-3956-3575 samuellynconleandro@gmail.com Universidade Estadual do Oeste do Paraná | Programa de Pós-Graduação Stricto-Sensu em Contabilidade Cascavel | Paraná | Brasil

Adhmir Renan Voltolini Gomes, Mestre http://orcid.org/0000-0003-2089-5924 adhmir.renan@gmail.com Universidade Estadual do Oeste do Paraná | Programa de Pós-Graduação Stricto-Sensu em Contabilidade Cascavel | Paraná | Brasil

Rafael Maximiano Ferreira, Mestre http://orcid.org/0000-0002-5517-5516 rafamaxf@gmail.com

Universidade Estadual do Oeste do Paraná | Programa de Pós-Graduação Stricto-Sensu em Contabilidade Cascavel | Paraná | Brasil

Silvana Anita Walter, Doutora http://orcid.org/0000-0003-1684-5465 silvanaanita.walter@gmail.com

Universidade Estadual do Oeste do Paraná | Programa de Pós-Graduação Stricto-Sensu em Contabilidade Cascavel | Paraná | Brasil

Recebido em 30/novembro/2018

Aprovado em 15/outubro/2019

Publicado em 02/janeiro/2020

Sistema de Avaliação: Double Blind Review

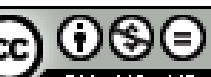

Esta obra está sob uma Licença Creative Commons Atribuição-Uso. 


\title{
RESUMO
}

O propósito dessa pesquisa é analisar a influência das abordagens metodológicas nas mídias sociais à luz dos princípios do conectivismo. O estudo foi construído e pautado nas contribuições associadas ao conjunto da tecnologia para os indivíduos, atrelado ao relevante papel das Instituições de Ensino Superior no processo educacional. A pesquisa é do tipo survey, delineada por uma abordagem quantitativa. Nesse sentido, foram aplicados questionários in loco para os acadêmicos do curso de Ciências Contábeis das instituições públicas de ensino, localizadas no estado do Paraná, que obtiveram nota cinco no exame de 2015 do Enade. Compreendeu a amostra o total de 516 respondentes. Considera-se que a percepção dos alunos sobre as abordagens possibilitou identificar quais são as abordagens que mais elevam a percepção sobre os princípios do conectivismo no ambiente acadêmico. Nessa perspectiva, mesmo que os acadêmicos não detenham os conhecimentos das abordagens metodológicas, são hábeis a indicar a sua percepção sobre os hábitos dos professores com os quais já conviveram, como também para demonstrar a sua concepção referente a esses hábitos. Os resultados também evidenciaram que quanto maior a percepção das limitações, maior será a percepção sobre as abordagens: tradicional, humanista, cognitivista e sociocultural.

Palavras-chave: Abordagens Metodológicas. Ciências Contábeis. Conectivismo. Desafios. Estratégias de Ensino.

\begin{abstract}
The main purpose of this paper is to analyze the influence of methodological approaches in social media about of the principles of connectivism. The study was based on the contributions associated to the technology set for individuals, linked to the relevant role of Higher Education Institutions in the educational process. The research is a survey, delineated by a quantitative approach. In this sense, questionnaires were applied in loco, for the academics of Accounting Sciences Course of the public educational institutions, located in the state of Paraná, with five score obtained in the 2015 exam of Enade. The sample contains a total of 516 respondents. It is considered that the students' perceptions about the approaches made it possible to identify which are the approaches that most raise the perception about the principles of connectivism in the academic environment. In this perspective, even if academics do not have the knowledge of methodological approaches, they are adept at indicating their perception of the habits of the teachers they have already lived with, to demonstrate your conception concerning these habits. The results also showed that the greater the perception of the limitations, the greater the perception about the approaches; traditional, humanistic, cognitive and sociocultural.
\end{abstract}

Keywords: Methodological Approaches. Accounting Sciences. Connectivism. Challenges. Teaching Strategies. 


\section{INTRODUÇÃO}

As redes sociais evoluíram de encontros técnicos e impessoais para encontros virtuais, visto que anteriormente a rede social tinha o significado de almoço de negócios de conferência e até de coquetel patrocinado. Nos dias atuais a abordagem evidencia o significado de algo novo, pautado na definição da conexão e no envolvimento em sites como Facebook, Google+, MySpace ou LinkedIn, YouTube, entre outros. Essas maravilhas tecnológicas possibilitam às pessoas fazerem conexões, fortalecerem e estabelecerem novas parcerias, além de poderem fazer uploads de informações (AGARWAL; MITAL, 2009).

Destaca-se que as mídias sociais fazem parte da cultura contemporânea e desempenham papéis cada vez mais relevantes, sendo substancial para o exercício da cidadania. Nessa perspectiva, são os professores, caracterizados como os profissionais que poderão colaborar com a formação dos cidadãos, que devem estar em condições de intervir dentro de um contexto social globalizado. Neste ambiente é privilegiado o acesso, o domínio e o uso efetivo da informação (BARBOSA; FERREIRA, 2013).

Por outro lado, os docentes devem estar preparados para utilizar as TIC's, na medida em que essas ferramentas possam ser um potencial na educação, pois os professores, quando integrados com esses conjuntos tecnológicos, terão a oportunidade de transformar as mídias em socialização do conhecimento. Indo além dos conceitos tecnológicos, torna-se necessário a superação do desconhecimento tecnológico, visando o discernimento de descobrir novas formas estratégicas de aprender e ensinar (BARBOSA; FERREIRA, 2013).

Contudo, em uma parte significativa das instituições de ensino, o acesso às mídias sociais ainda é bloqueado ou filtrado (GREENHOW, 2011). Com base nisso, a principal retórica é sustentada sobre o pressuposto de que esses recursos fomentam a dispersão dos acadêmicos, resultando, consequentemente, em uma redução considerável da capacidade dos educadores de pensarem e explorarem essas ferramentas como novos espaços altamente envolventes e interativos (BARTOW, 2014).

$\mathrm{Na}$ área da Tecnologia da Informação e Comunicação, bem como na área da Contabilidade, o tema ainda é pouco abordado no âmbito nacional (CRUZ, 2015). Entretanto, em outras áreas do conhecimento, as mídias sociais já possuem uma abordagem consolidada (DIAS; COUTO, 2011; DOTTA, 2011; BARBOSA; FERREIRA, 2013), assim como no âmbito internacional (BARCZYK; DUNCAN, 2011; BUZZARD; CRITTENDEN; CRITTENDEN; MCCARTY, 2011; CAO; AJJAN; HONG, 2013; BARTOW, 2014). 
Diante disso, considerando a importância e as contribuições associadas ao conjunto da tecnologia para os indivíduos, além do relevante papel das Instituições de Ensino Superior no processo educacional, verifica-se que os estudos que visam analisar as mídias sociais com as estratégias de ensino em Contabilidade merecem aprofundamento. Assim, torna-se pertinente a indagação deste artigo: Qual a influência das abordagens metodológicas nas mídias sociais à luz dos princípios do conectivismo?

A resposta desta pergunta possibilita compreender como as abordagens metodológicas impactam no uso das mídias sociais no ensino. Salientando-se que o aluno é o agente principal desse processo, é de suma importância se obter uma visão holística sobre as abordagens metodológicas, entendendo-se que o estudante de Ciências Contábeis é um indivíduo que também trabalha. Os princípios do conectivismo poderão contribuir com o processo de ensino, pois nesses a aprendizagem é definida como um conhecimento acionável, isto é, podendo residir fora dos indivíduos (SIEMENS, 2005).

Dessa forma, o estudo está estruturado em cinco seções: Na primeira seção é apresentada a introdução; posteriormente, na segunda seção, são apresentados os aspectos relacionados ao referencial teórico, abordados para fundamentação das hipóteses trabalhadas na pesquisa; na seção seguinte, são detalhados os procedimentos metodológicos utilizados, já na quarta seção é trabalhada a apresentação e a análise dos resultados; por último, na quinta seção, são discutidas as considerações finais, evidenciando os principais achados, limitações e sugestões de futuras pesquisas.

\section{REFERENCIAL TEÓRICO}

Nestes tópicos estão descritos o embasamento teórico e as hipóteses utilizadas para a construção do referencial teórico. Primeiramente, são discutidos os aspectos relacionados aos desafios, posteriormente, são apresentadas as abordagens associadas ao cognitivismo e, por fim, são detalhadas as abordagens metodológicas.

\subsection{DESAFIOS}

Neste estudo os desafios abordados referem-se às limitações, às concepções pedagógicas e à utilização das mídias sociais no processo educacional de ensino e aprendizagem. Sendo assim, as potenciais limitações do uso das mídias sociais e da Web 2.0 como recursos metodológicos nas salas de aula abordam desde aspectos referentes à 
disponibilidade desses recursos, à danificação dos conteúdos, à conveniência dos serviços, até o plágio propriamente dito com relação aos conteúdos disponíveis (HARRIS; REA, 2009).

Os conteúdos disponibilizados na internet podem estar suscetíveis a ações com o propósito de danificá-los ou até mesmo sabotá-los. Destarte, a capacidade do usuário pode levar o mesmo a práticas contínuas de simplesmente copiar e colar informações, sendo que com essa facilidade os recursos podem facilitar o plágio e, por outro, lado legitimar o comportamento de outros usuários. Outro fator agravante diz respeito ao nível de abertura das mídias sociais, isto é, a publicidade do conteúdo produzido, pois as escritas e as respostas ficam disponíveis para diversos usuários visualizarem. Essa exposição sem restrições do conteúdo promove certo desconforto, pelo fato dos discentes crerem que a comunicação deveria ser apenas entre eles e o instrutor (HARRIS; REA, 2009).

Ainda, no que tange às informações pessoais, caracterizadas como privadas, no sentido de construir o relacionamento educativo propriamente dito, também podem acarretar em pontuais problemas relacionados a transtornos, como por exemplo, o fomento a circulação de conteúdos de natureza desarmoniosa em ambientes formados por determinados grupos de indivíduos mais próximos (BARCZYK; DUNCAN, 2011).

$\mathrm{O}$ constructo referente às limitações das mídias sociais em sala de aula é composto pelos conceitos abordados por Harris e Rea (2009) e Barczyk e Duncan (2015). Nesse sentido, os conceitos apresentados pelos respectivos autores são construídos e fundamentados em aspectos associados às condições de acessibilidade nas ferramentas e conectividade, bem como na segurança no compartilhamento das informações, na prática contínua do plágio, na privacidade de conteúdo e nas consequências morais. Destarte, propomos a seguinte hipótese:

$\mathrm{H}_{1}$ : As limitações influenciam as abordagens metodológicas de Mizukami (1986).

Destaca-se, mediante a hipótese proposta, que os professores tomam decisões pedagógicas dentro e fora das redes sociais. Assim, o intuito da proposição é melhorar o gerenciamento, a comunicação, a facilitação do compartilhamento, a acessibilidade e a transposição de barreiras referentes ao espaço e ao tempo. Diante disso, as decisões pedagógicas dos professores quando combinadas com as mídias sociais podem promover significativamente a eficiência do processo de ensino e aprendizagem, pois proporcionam uma abertura relevante para a construção de um ambiente interativo, sujeito a novas regras e oportunidades, dado a disponibilidade de conteúdos em qualquer tempo (BARTOW, 2014). 
Contudo, as instituições de ensino protegem os novos espaços por meio do monitoramento e disciplina. Logo, as escolhas pertinentes dos docentes consistem na adoção das plataformas de ensino com o intuito de proteger e trabalhar com ambientes disponíveis, sejam eles formais ou informais. Outro desafio emergente refere-se à avaliação contínua e crítica dos conteúdos didáticos com os alunos (BARTOW, 2014). Nesse sentido, a estratégia direcionada pela utilização de equipes virtuais, além das que são oferecidos online, pode ser considerada um aprimoramento pedagógico (BUZZARD et al., 2011).

Dessa forma, observa-se que as mídias sociais podem ser utilizadas para alcançar os objetivos da taxonomia de Bloom referentes à aprendizagem, proporcionado a fundamentação para o construtivismo, a conectividade e as comunidades. Cabe destacar que as mídias sociais possibilitam o aprendizado de diferentes formas e, nessa perspectiva, também permitem diferentes formas de aplicação e avaliação do conteúdo proposto (BOSMAN; ZAGENCZYK, 2011). Referente às tomadas de decisões pedagógicas com as mídias sociais, propomos a seguinte hipótese:

$\mathrm{H}_{2}$ : As concepções pedagógicas influenciam os princípios da teoria do conectivismo nas redes sociais.

Destarte, muitos professores já utilizam alguma mídia social como ferramenta de apoio em suas aulas. Essa prática auxilia no relacionamento e na comunicação com os estudantes, mesmo tendo diferenças substanciais na utilização referentes às idades dos envolvidos. Constata-se, com isso, que os docentes também partilham da ideia de que as mídias sociais têm valor para o ensino (PARRY, 2010).

Considerando que as ferramentas inerentes às mídias sociais estão disponíveis e podem ajudar no engajamento para a construção de um melhor processo de ensino e aprendizagem para os alunos, deveriam ser observadas e tratadas, nessa perspectiva, visando à incorporação aos currículos, não de forma exclusiva, mas complementar. Assim, as mídias sociais podem ser utilizadas como um meio de instrução, de forma responsável e como ferramenta de apoio no processo educacional (BARCZYK; DUNCAN, 2011). Dessa forma, a construção da hipótese referente ao desafio da utilização das mídias sociais é proposta da seguinte forma:

$\mathrm{H}_{3}$ : A Utilização das mídias sociais nas salas de aula influencia positivamente os princípios da teoria do conectivismo nas redes sociais. 
É evidente salientar a importância do papel do professor nesse processo, uma vez que a participação efetiva e o acompanhamento sistemático na utilização dessas ferramentas tecnológicas, poderão contribuir significativamente para maximização dos resultados, isto é, da aprendizagem proposta no processo educacional dos acadêmicos. Dessa forma, determinados as hipóteses e a influência esperada sobre as limitações, no tópico seguinte são abordados os princípios da teoria do conectivismo proposto por Siemens (2005).

\subsection{CONECTIVISMO}

A teoria do conectivismo refere-se à integração dos princípios das teorias do caos, de rede, da complexidade e da autorregulação. Nesta construção, o aprendizado também ocorre em um ambiente enigmático, o qual não está sobre o controle do indivíduo. Assim, a aprendizagem é definida como um conhecimento acionável, isto é, também pode residir fora dos indivíduos, bem como dentro de uma determinada organização ou em um banco de dados. Essas conexões relativas a um estabelecido conjunto de informações especializadas permitem os indivíduos aprenderem mais sobre o conteúdo. Com isso, são definidas como fontes mais importantes do que o estado atual de conhecimento dos indivíduos (SIEMENS, 2005).

Destarte, o ponto de partida do conectivismo é o indivíduo, porém o conhecimento pessoal é composto por uma rede, que por sua vez alimenta com informações as organizações e as instituições. As informações remetem a uma rede que fornece a aprendizagem individual, sendo caracterizado como um ciclo de desenvolvimento do conhecimento pessoal, permitindo que os estudantes permaneçam em constante atualização sobre seus campos de interesse por meio das conexões formadas (SIEMENS, 2005).

Neste estudo, foram abordados os seguintes princípios do conectivismo para as mídias sociais: (a) a aprendizagem e o conhecimento recaem sobre a diversidade de opiniões; (b) a capacidade de saber mais é relevante do que o conhecimento atual; (c) a necessidade de nutrir e manter conexões torna-se fundamental para facilitar a aprendizagem contínua e; (d) o conhecimento preciso e atualizado é a finalidade das atividades de aprendizagem conectivista (SIEMENS, 2005).

É importante salientar que a aprendizagem e o conhecimento recaem sobre a diversidade de opiniões (SIEMENS, 2005), uma vez que as mídias sociais envolvem os alunos no processo de aprendizagem. Além de proporcionar a melhoria na compreensão do material apresentado, o mundo torna-se a sala de aula, pois com o grande número de 
tecnologias fundamentadas na internet, a classe não precisa ficar apenas no confino de um espaço. Com isso, os alunos podem trabalhar facilmente, além dos limites físicos, com pessoas de diferentes origens, valores e crenças culturais (HARRIS; REA, 2009).

No que tange ao princípio referente à capacidade de saber mais, o mesmo é caracterizado como mais relevante do que o conhecimento atual (SIEMENS, 2005), visto que nas mídias sociais se perpetua com base na vasta fonte de conhecimento disponibilizada para as instituições de ensino, permitindo-se novas formas de comunicação e de cunho inovador e palpável (FACINELLI, 2009). Com isso, as mídias sociais não só interrompem a educação de várias maneiras, mas também põem em xeque as construções que predominam nas instituições de ensino, tanto entre professores e alunos, quanto ao ensino e aprendizagem (LUKE, 2006). Além disso, sempre houve o aprendizado autodirigido, no entanto, a internet apenas permite que isso ocorra de forma muito ampla. $\mathrm{O}$ papel das redes sociais na sala de aula é um discurso fora do habitual da educação e das instituições de ensino relacionadas às ciências da aprendizagem (GEE, 2004). A utilização das mídias sociais na sala de aula coloca os professores no papel de alunos, pois faz com que o aprendizado seja um atributo chave (CARLSON, 2008).

Referente ao princípio da necessidade de nutrir e manter conexões para facilitar a aprendizagem contínua (SIEMENS, 2005), entende-se que as mídias sociais podem ser usadas com o intuito de interação entre os alunos em quase todas as disciplinas (BARCZYK; DUNCAN, 2011). Além disso, tanto a colaboração quanto a competição podem aumentar a aprendizagem, sendo que os benefícios da colaboração já são bem disseminados e a competição evidencia uma chance para ampliação do conhecimento (HARRIS; REA, 2009).

A disseminação da tecnologia digital em âmbito global e, mais recentemente, das mídias sociais, possibilitou a interação entre os indivíduos em ambientes participativos (CARLSON, 2008). Em consequência disso, esse aumento na disseminação das mídias digitais provocou uma expoente influência na construção das interações entre professores e alunos, que já existia de maneira pouco expressiva no ambiente da web (BUZZARD et al., 2011).

O conhecimento preciso e atualizado, finalidade das atividades de aprendizagem conectivista (SIEMENS, 2005), quando relacionado às mídias sociais, transforma a sala de aula num ambiente disponível constantemente, 24 horas por dia. Dessa forma, o aprendizado ultrapassa o confinamento de uma reunião trivial no campus universitário. Logo, o 
aprendizado também pode acontecer de forma assíncrona, sendo necessário apenas que o discente tenha o interesse em procurá-lo (HARRIS; REA, 2009).

Assim, os meios pelos quais os docentes articulam o processo de ensino estão direcionados aos objetivos almejados nas estratégias de ensino (ANASTASIOU; ALVES, 2004) e, nesse sentido, observa-se a importância da adoção de mecanismos interativos visando à retenção e o estímulo sobre o interesse dos acadêmicos com o processo de ensino e aprendizagem. Nessa concepção, no próximo tópico são discutidos os conceitos associados às abordagens metodológicas.

\subsection{ABORDAGENS METODOLÓGICAS}

As abordagens metodológicas de acordo com Mizumaki (1986) são classificadas como: (I) tradicional; (II) comportamentalista; (III) humanista; (IV) cognitivista e; (V) sociocultural. Assim, a abordagem tradicional (I) considera que o processo de ensinoaprendizagem não tem embasamento teórico empírico válido, seja de forma implícita ou explicita. A fundamentação dessa abordagem tem como base a prática de replicação por parte dos docentes no decorrer dos anos. Concentra-se no professor como foco principal, e os alunos apenas realizam o proposto.

Já a abordagem comportamentalista (II) insere-se com o empirismo e o conteúdo é compartilhado e pautado no direcionamento de priorizar as situações, os quais propiciam ao estudante a condição de um indivíduo receptor de informações e reflexões. Nessa abordagem, o processo decorre-se por conjuntos comportamentais que podem ser modificados. No tocante ao processo de avaliação, tem-se o intuito de observar o comportamento absorvido pelos discentes (MIZUKAMI, 1986).

$\mathrm{Na}$ abordagem humanista (III) tem-se o direcionamento observado no indivíduo, assim, nessa abordagem as relações interpessoais e a contribuição são provenientes dos resultados dessa interação. O professor é um facilitador da aprendizagem, pois individualmente não transmite o conhecimento. Considera-se que as atividades decorrem da interação com o contexto social em que os indivíduos estão inseridos e o processo consiste na reconstrução de experiências (MIZUKAMI, 1986).

A abordagem cognitivista (IV) é relacionada com aspectos psicológicos dos indivíduos, pois o docente nesse processo tem o papel de orientador. O professor é caracterizado pela postura de propor desafios e soluções para os alunos e, por meio das 
orientações, resguarda uma independência intelectual dos discentes. E ainda, resguarda-se uma independência intelectual do aluno por meio das orientações. Contudo, a participação dos docentes deve ser significante no que se refere ao estímulo sobre o aprendizado relacionado às experiências dos alunos (MIZUKAMI, 1986).

Com relação à abordagem sociocultural (V), a mesma refere-se ao enfoque sobre os aspectos inerentes às relações culturais e políticas. Verifica-se, então, que o conhecimento se associa as perspectivas da conscientização por meio de estímulos na reflexão e na prática. Esse processo direciona a expectativa do indivíduo referente a uma realidade, propiciando uma reflexão crítica. O professor tem um relacionamento construído de forma horizontal com os estudantes e não hierárquico. Essa postura exige a inversão dos papéis entre o professor e alunos, pois o diálogo é um dos principais elementos que possibilita a interação horizontal (MIZUKAMI, 1986).

Desse modo, com base nos conceitos apresentados nos tópicos referentes à teoria do conectivismo e das abordagens metodológicas, propomos as seguintes hipóteses de pesquisa:

$\mathrm{H}_{4}$ : A diversidade de opiniões das mídias sociais nas salas de aula influencia positivamente as abordagens metodológicas.

$\mathrm{H}_{5}$ : A capacidade de saber mais nas mídias sociais influencia positivamente as abordagens metodológicas.

$\mathrm{H}_{6}$ : A necessidade de nutrir e manter conexões para facilitar a aprendizagem contínua influencia positivamente às abordagens metodológicas.

$\mathrm{H}_{7}$ : As abordagens metodológicas influenciam positivamente a necessidade de nutrir e manter conexões para facilitar a aprendizagem contínua.

Apresentadas essas hipóteses, o tópico a seguir demonstra os procedimentos adotados na metodologia da pesquisa.

\section{METODOLOGIA}

O estudo em questão é realizado por meio de uma pesquisa do tipo survey, nesta metodologia tanto a coleta quanto a quantificação dos dados são uma fonte permanente de informações. Além disso, a pesquisa pode ser considerada experimental, uma vez que verifica a influência das abordagens metodológicas sobre as mídias sociais de acordo com a percepção dos alunos (LIBBY; BLOOMFIELD; NELSON, 2001). Dessa forma, a pesquisa em questão 
é definida por uma abordagem quantitativa, pois abarca uma técnica de análise multivariada (HAIR JR. et al., 2005).

Assim, a coleta deste estudo é realizada com dados primários que são coletados de uma amostra de indivíduos (HAIR JR. et al., 2005). A amostra em voga refere-se aos acadêmicos dos cursos de Ciências Contábeis das IES públicas, localizadas no estado do Paraná, que obtiveram conceito cinco no Enade na última avaliação ocorrida em 2015.

O questionário aplicado contém quarenta questões com os conceitos encontrados na teoria. Dessa forma, as referidas questões foram estruturadas em três partes: a primeira com os dados das variáveis categóricas referente ao perfil dos respondentes; na segunda parte, assim como na terceira, foram abordados conceitos sobre os desafios, o conectivismo e as abordagens metodológicas. Além disso, as questões foram estruturadas de acordo com a escala Likert com diferencial semântico, na qual os polos são antagônicos, bipolares (MALHOTRA, 2006). Optou-se, portanto, por uma escala de sete pontos, sendo (1) para discordo totalmente, e (7) para concordo totalmente.

Figura 1 Relações Propostas

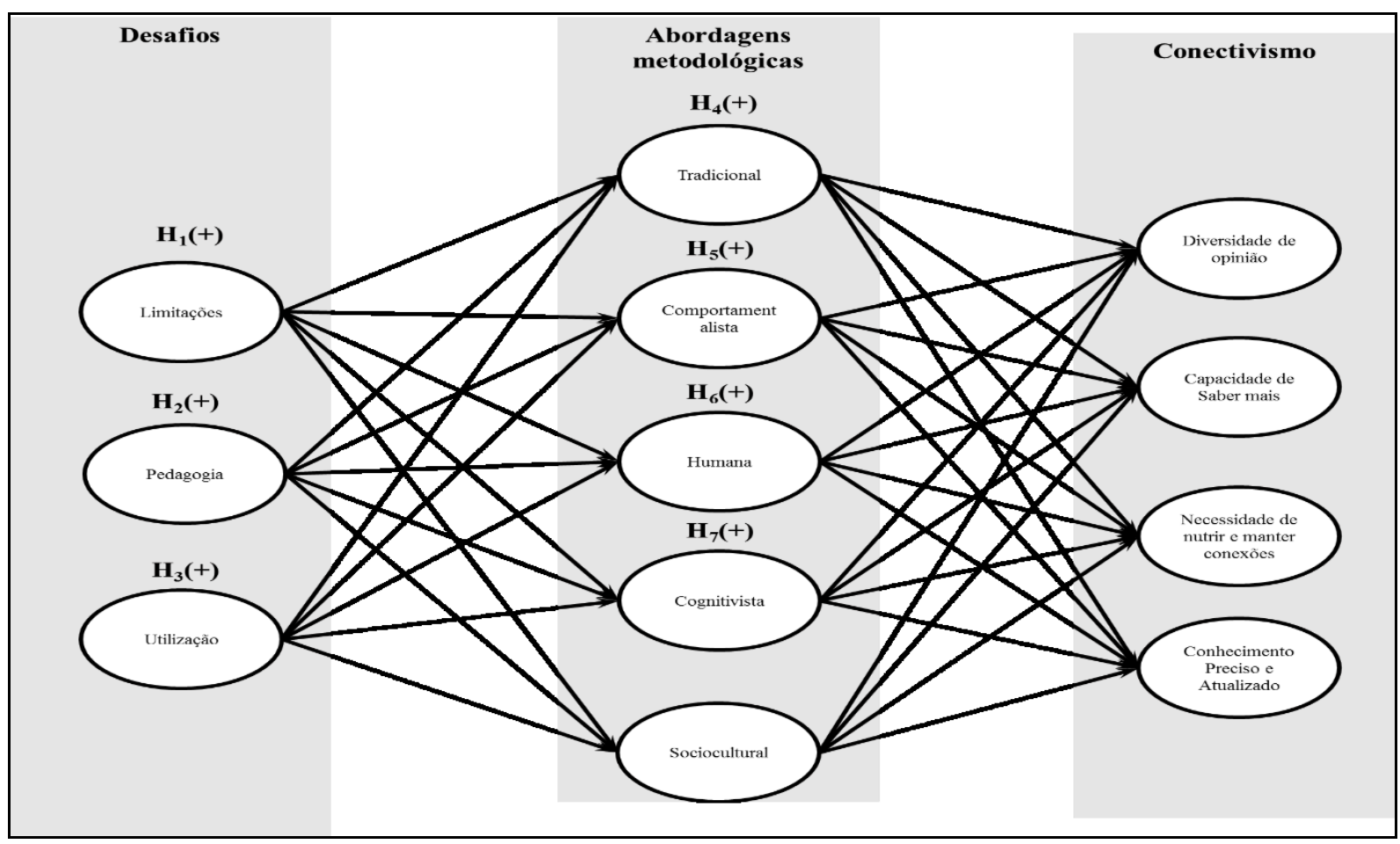

Fonte: elaborado pelos autores (2017). 
Conforme abordado no referencial teórico, as relações estão descritas de acordo com a Figura 1. Em análise mais ampla, os desafios detêm efeito sobre as abordagens metodológicas, ao passo que as abordagens metodológicas têm efeito sobre os princípios do conectivismo.

No tocante à aplicação do instrumento de coleta de dados, o mesmo foi impresso e distribuídos in loco para as turmas presenciais, totalizando o montante de 516 acadêmicos, já excluídos os questionários preenchidos indevidamente. Nesse sentido, sete desses questionários apresentaram pelo menos uma questão em branco, adotando-se dessa forma a média para a respectiva questão. Além disso, com a possibilidade de conhecimento da população, que seguramente não é superior a 800 acadêmicos, segue a Equação 1 demonstrando o cálculo do erro amostral.

$$
n_{0}=\left(\frac{1}{0,05}\right)^{2}=400 \quad n=\frac{(800 \times 400)}{(800+400)}=267
$$

Diante disso, devido à amostra coletada ser maior que 267, a análise em questão, pode ser considerada com um nível de precisão de ao menos 5\% de significância. Na Figura 1 é apresentado o construto da pesquisa, com a modelagem das equações estruturais proposta na pesquisa.

Para auxílio nas análises foi utilizado o software SmartPLS e planilhas eletrônicas para a organização dos dados. A modelagem de equações estruturais permite ao pesquisador maior flexibilidade em comparação com outros métodos multivariados. Contudo, o uso adequado do método é preocupação prioritária com a teoria em questão.

As equações estruturais podem fornecer um teste confirmatório para uma série de relações causais, porém também é possível utilizá-la de forma exploratória (HAIR JR. et al., 2005). Por conseguinte, na próxima seção são discutidas as análises e a apresentação dos resultados.

\section{ANÁLISE E APRESENTAÇÃO DOS RESULTADOS}

O tópico em questão está organizado através dos pressupostos, do efeito das limitações das mídias sociais perante as abordagens metodológicas e pelas abordagens metodológicas perante o conectivismo nas mídias sociais. 


\section{1 PRESSUPOSTOS}

A operacionalização da análise dos dados foi executada por meio das equações estruturais pelo método bootstrapping, pois neste método os coeficientes são mais estáveis e mais confiáveis, até mesmo em amostras pequenas ou com presença de outliers (CHIQUOINE; HJALMARSSON, 2009). Este método permite verificar a significância das estimativas (AZEVEDO et al., 2012). No que concerne a este estudo, optou-se por 500 interações.

As validades convergentes são observadas através das observações das variâncias médias extraídas (AVE). As variáveis do modelo ficaram superiores a 0,5 , o que indica que as variáveis latentes são explicadas por cada um dos constructos, ou o quanto em média as variáveis se correlacionam positivamente com seus respectivos constructos, destarte o modelo converge a um resultado satisfatório (FORNELL; LARCKER, 1981). Com relação a validade convergente, o Alfa de Cronbach dos constructos ficaram acima de 0,7, considerado satisfatório para pesquisas exploratórias (HAIR et al., 2014).

Entretanto, os coeficientes de determinação obtidos foram próximos de $10 \%$, este resultado é esperado por se tratar de percepções de abordagens metodológicas dos acadêmicos, e também por representar a utilização das mídias sociais voltadas para o ensino, o que ainda não é usual no âmbito acadêmico. Além disso, a ampla gama de finalidades para o uso das mídias sociais, como por exemplo, comerciais, relacionamentos e entretenimentos em geral, pode justificar esse resultado.

Ao se verificar o valor da raiz quadrada de AVE, nota-se que todos foram superiores ao coeficiente de correlação entre as demais variáveis latentes, portanto, o modelo possui validade discriminante (FORNELL; LACKER, 1981). Os valores alcançados para a colinearidade obtida entre as variáveis por meio da Variance Inflation Factor (VIF) comprovaram a inexistência desta. Com isso, existe uma relação linear entre variáveis explicativas, pois os valores considerados aceitáveis ficam entre 1 e 10 (CORRAR; PAULO; DIAS FILHO, 2007).

\subsection{EFEITOS ENCONTRADOS}

Ao se analisar o efeito dos desafios sobre as abordagens metodológicas, percebe-se que quanto maior a percepção das limitações, maior serão as percepções referentes às abordagens metodológicas; Tradicionalista, Humanista, Cognitivista e Sociocultural. Com 
relação à percepção dos acadêmicos sobre as limitações, verificou-se o maior efeito de influência na abordagem cognitivista $(0,122)$, com um nível de 5\% de significância. Diante disso, verifica-se que a respectiva abordagem está relacionada ao professor inclinado à postura de orientador, possibilitando aos acadêmicos certa independência na construção do conhecimento. Em seguida, posicionaram-se por nível de influência as abordagens, tradicional $(0,119)$, sociocultural $(0,112)$ e humanista $(0,099)$.

Dessa forma, esses resultados sugerem que quanto maior for a percepção das limitações dos aspectos das mídias sociais, maior será a percepção voltada à abordagem metodológica tradicional. Porém, as limitações exercem o mesmo efeito sobre a percepção dos hábitos humanistas, cognitivistas e socioculturais. Com ressalva evidenciada para a concepção das abordagens comportamentalistas, pois nesse enfoque emerge a prática docente no exercício profissional do professor e, nesse processo os conjuntos comportamentais podem ser modificados conforme a necessidade (HARRIS; REA, 2009).

A Figura 2 demonstra os efeitos comprovados e não comprovados dos desafios nas abordagens metodológicas e das mesmas nos princípios do conectivismo.

Figura 2 Modelagem das equações estruturais com os efeitos encontrados.

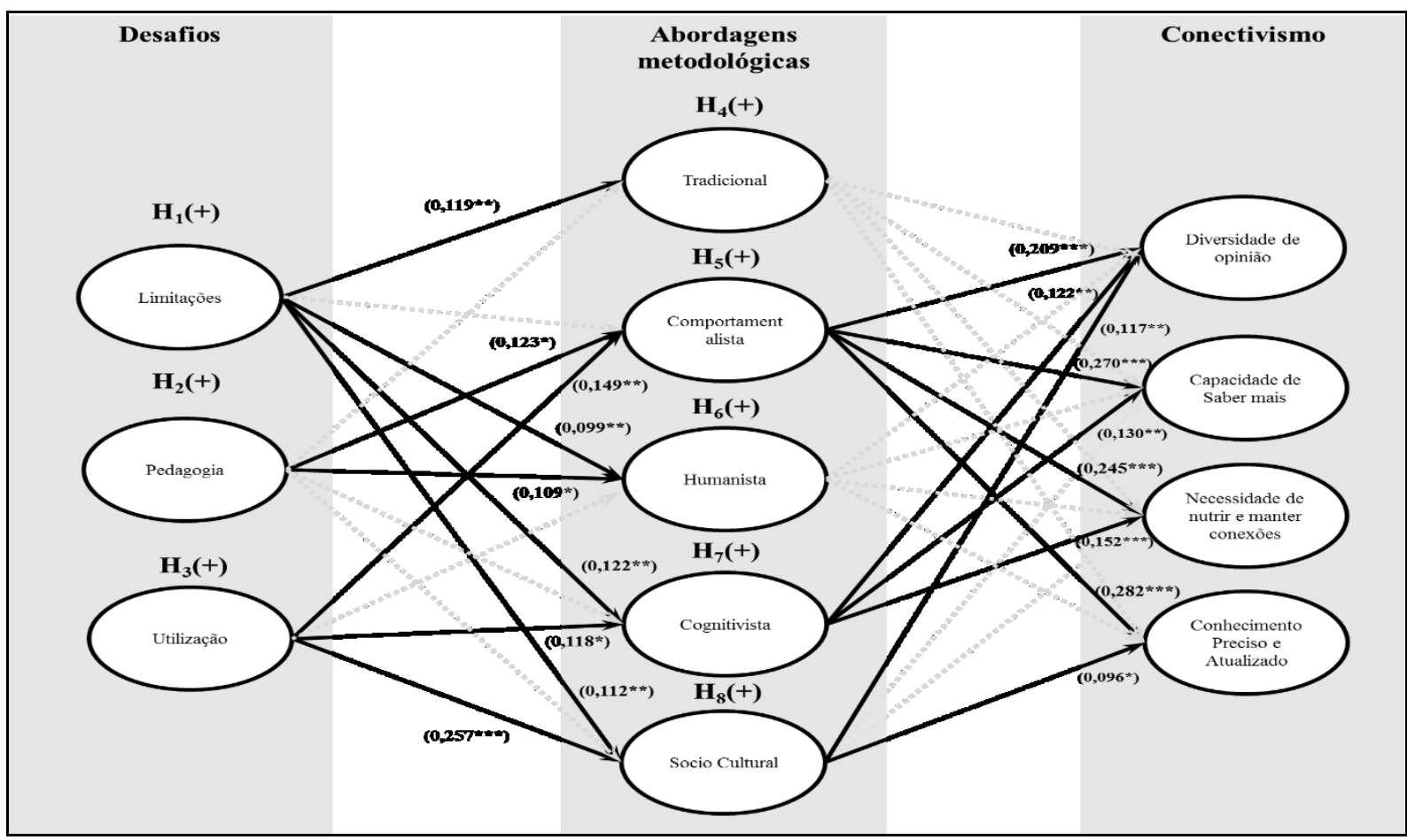

Nota: ***coeficientes com $\mathbf{p}$ valor $<0,01 * *$ coeficientes com $\mathbf{p}$ valor $<0,05 *$ coeficientes com $\mathbf{p}$ valor $<\mathbf{0 , 1 0}$

Fonte: Dados da pesquisa (2017). 
As concepções acadêmicas influenciam apenas as abordagens comportamentalistas e humanistas, com nível de significância de $10 \%$, de forma positiva. Assim, considerando o enfoque comportamentalista, a percepção de que as mídias sociais expandem as concepções de avaliação dos professores, melhoram o comportamento do assunto, expandem os meios de aprendizagem e ainda possibilitam identificar e avaliar diversas situações práticas/teóricas, influencia na percepção de que os professores devem compartilhar o conteúdo e priorizar as situações (BOSMAN; ZAGENCZYK, 2011).

Além disso, constata-se que a percepção das concepções metodológicas também influencia o tratamento sobre a percepção das abordagens humanistas, pois nestas o professor possui um papel de facilitador e que, individualmente, não transmite o conhecimento. Dentre as abordagens que não obtiveram significância, destaca-se a tradicional, prática de ensino adotada pelos docentes, pautada sobre o direcionamento da replicação do conteúdo no decorrer do exercício profissional docente (MIZUKAMI, 1986).

Os aspectos relacionados à utilização das mídias sociais também exercem influência sobre as abordagens sociocultural, cognitivista e comportamentalista, na ordem de 0,257, 0,118 e 0,109 , respectivamente. Nesse sentido, as percepções sobre a utilização das mídias sociais verificadas referem-se especificamente às situações dos professores utilizarem vídeos, blogs, podcasts em suas aulas, bem como sobre a oportunidade de possibilitar o engajamento dos alunos, e ainda sobre a utilização das mídias sociais como influenciadoras das percepções referentes às abordagens metodológicas dispostas na pesquisa (PARRY, 2010; BARCZYK; DUNCAN, 2011).

Todavia, não foi possível perceber uma influência significativa na abordagem humanista. Cabe destacar que nessa abordagem metodológica o processo de aprendizagem é necessariamente pessoal, com ênfase direcionada ao sujeito, uma vez que o conteúdo discutido deve estar associado às experiências vivenciadas pelos acadêmicos e, nesse contexto, o professor possui o papel de estimular as condições para que o aluno concretize o aprendizado proposto (MIZUKAMI, 1986).

Assim, diante dessas constatações, verifica-se que o perfil dos acadêmicos retrata uma realidade voltada ao estímulo e aos desafios propostos no decorrer do processo de ensino e aprendizagem. Com isso, emerge a importância da participação efetiva do docente na medida em que se adotem as mídias sociais como uma estratégia metodológica de ensino. Observa-se que as percepções dos acadêmicos sobre as questões apresentadas estão atreladas a 
participação do docente no processo, no sentido de evitar possíveis dispersões e mau uso dessas ferramentas.

Com essas limitações discutidas no que concerne aos efeitos das mídias sociais, entende-se que a percepção de aplicação de abordagem tradicional como metodologia de ensino pelos acadêmicos não foi capaz de explicar os constructos da teoria do conectivismo. Tais resultados são suportados pelos achados de Siemens (2005), visto que a teoria do conectivismo defende as conexões como um conjunto de informações especializadas que permitem ao acadêmico aprender de maneira mais eficiente, ao passo que na abordagem tradicional de ensino, o professor é visto como o foco principal do processo educacional e o aluno apenas realiza o que lhe é proposto (MIZUKAMI, 1986).

A percepção dos alunos sobre a abordagem comportamentalista possui efeito positivo sobre as percepções referentes à teoria do conectivismo nas mídias sociais. Destarte os acadêmicos se sentem envolvidos no processo de aprendizagem (HARRIS; REA, 2009), pois são estimulados a adotar práticas de estudo autodirigido (LUKE, 2006), criando-se um espaço mais participativo e reflexivo dentro da sala de aula (CARLSON, 2008). Por ser um espaço de reflexão, é possibilitado ao acadêmico a obtenção do conhecimento através das preferências múltiplas, flexibilizando-se o processo de aprendizagem (BARRON, 2006; GREENHOW, 2011; CAO; AJJAN; HONG, 2013).

Nos efeitos encontrados observou-se que os acadêmicos demonstraram ter maior facilidade de acesso as mídias sociais como parte integrada do processo de ensino/aprendizagem quando o professor adota uma abordagem comportamentalista (MIZUKAMI, 1986), visto que este docente visa proporcionar ao estudante, através do compartilhamento de conteúdo, a construção de competências. Nessa perspectiva surge a necessidade de coordenadores de curso e docentes adotarem práticas que levem os acadêmicos a estágios mais avançados de aprendizado, possibilitando que os mesmos sejam mais atuantes e reflexivos dentro de sua realidade.

O constructo referente à abordagem humanista não apresentou efeito interno sobre as dimensões da teoria do cognitivismo nas mídias digitais. Isto pode indicar que os acadêmicos não percebem a abordagem humanista nos docentes, visto que nesta abordagem o processo de ensino/aprendizagem é centralizado no aluno, tendo como finalidade a criação de condições que facilitem a aprendizagem de forma a ser possível o desenvolvimento intelectual e 
emocional. A maior característica desta abordagem é o foco no próprio aluno (MIZUKAMI, 1986).

Destarte, pela abordagem cognitiva estar relacionada com os aspectos psicológicos dos indivíduos, denota ao professor o papel de orientador. Assim, a percepção dos acadêmicos é inerente aos aspectos, desafios e soluções propostos pelos professores (MIZUKAMI, 1986). Por outro lado, as mídias sociais podem possibilitar o envolvimento dos alunos no processo de ensino (HARRIS; REA, 2009), proporcionando o trabalho com alunos de diferentes crenças e valores. Assim obteve-se o efeito positivo dessa abordagem no conectivismo analisado, ao nível de significância de 5\%.

Com isso, quanto maior a percepção do acadêmico inerente às práticas cognitivistas, maior será a percepção sobre os benefícios da diversidade de opiniões contidas nas mídias sociais. Portanto, a postura de propor desafios e soluções, mesmo que os professores resguardem a independência intelectual dos alunos, é compreendida como fator determinante para o envolvimento com as mídias sociais.

Este resultado indica que a diversidade de opiniões do conectivismo reflete diretamente nas posturas cognitivistas dos professores nas salas de aula. Se os docentes tiverem o papel de orientador com uma participação significativa, envolvendo os alunos com as mídias sociais, é fato que, podem aumentar tanto o grau de confiança com o conteúdo quanto dinamizar o processo de ensino, beneficiando toda a aprendizagem.

A capacidade de saber mais se refere ao vasto conhecimento disponibilizado pelas mídias sociais (SIEMENS, 2005), tanto para se comunicar quanto para disponibilizar o conhecimento (FACINELLI, 2009). Com isso, a percepção dos acadêmicos sobre o papel do professor como de orientador no processo de ensino detém um efeito positivo nessa concepção do conectivismo nas mídias sociais, visto que o nível de significância obtido foi igual a $5 \%$.

Logo, a percepção dos acadêmicos sobre os hábitos cognitivistas dos professores aumentam o discernimento de que as mídias sociais são uma maneira inovadora e palpável, possibilitando novas formas de aprendizado, seja autodirigido ou não, formal ou informal, bem como desafiando os docentes a buscar mais conhecimento. Nesse entendimento, os professores com hábitos cognitivistas também conseguem facilitar a capacidade de saber mais dos acadêmicos nas mídias sociais. 
Sob a perspectiva de nutrir e manter conexões nas mídias sociais, a percepção sobre os hábitos cognitivistas também influencia de forma positiva essa abordagem. Esse fato pode ser compreendido devido aos aspectos voltados a interação, colaboração e competição entre os alunos, bem como sobre os espaços participativos e interativos com os professores. Fatores estes que estão em consonância com o papel de orientar e desafiar os alunos, presentes na abordagem dos professores. Precisamente, o nível de significância deste efeito é equivalente a 1\%. Não obstante, se observada a percepção sobre as práticas cognitivas, os professores conseguiram exercer um efeito positivo na utilização de três princípios do conectivismo no ambiente acadêmico.

Na perspectiva voltada à abordagem sociocultural, o conhecimento se relaciona com a conscientização por meio dos estímulos na reflexão e na prática. Destaca-se que o relacionamento com o acadêmico ocorre de forma horizontal, tendo também uma influência positiva quando se relaciona com a diversidade de opiniões.

Este resultado sugere que as percepções sobre as relações políticas e culturais são aumentadas pela percepção inerente as práticas socioculturais. Dessa forma, as diversidades de opiniões culturais e políticas detêm um ambiente propício nas mídias sociais para o professor dialogar. Porém, ressalta-se o efeito das limitações referentes aos danos morais que pode ocorrer nas diversidades de opiniões caso não utilizadas com responsabilidade.

A finalidade das abordagens conectivistas refere-se à exatidão e atualização dos conhecimentos de forma constante (SIEMENS, 2005). Quando se compara com a percepção sobre a abordagem sociocultural nota-se que o ambiente cultural, político e outros, detêm mudanças constantes. Assim, o efeito encontrado foi estatisticamente significante ao nível de $5 \%$ e considerado positivo.

Esse resultado sugere que o ambiente das mídias sociais, no que tange ao conhecimento preciso e atualizado, estimula os acadêmicos a refletir determinadas realidades culturais e políticas e ainda realizar reflexões críticas a respeito, bem como enfatiza-se que o relacionamento horizontal com os acadêmicos alavanca os estímulos de conscientização necessários para usufruir das mídias sociais.

Apresentadas as diferentes abordagens metodológicas e os diferentes princípios é necessário identificar quais são os que mais propiciam a exploração dos princípios do conectivismo. Nessa perspectiva, o próximo tópico aborda a exploração das abordagens metodológicas no princípio do conectivismo. 


\subsection{HABILIDADE DE EXPLORAR AS MÍDIAS SOCIAIS}

Identificam-se que determinadas abordagens metodológicas podem deter menos ou mais barreiras em comparação às outras abordagens, pois umas elevam as percepções dos princípios do conectivismo e outras não exercem influências. Observa-se pela Tabela 2 as abordagens que mais exploram os princípios do conectivismo.

Tabela 2 Habilidades de explorar os princípios das abordagens metodológicas

\begin{tabular}{ll}
\hline Abordagens Metodológicas & Capacidade de explorar o Conectivismo \\
\hline Tradicional & Nenhum princípio \\
\hline \multirow{2}{*}{ Comportamentalista } & Diversidade de Opiniões \\
& Capacidade de Saber Mais \\
& Necessidade de Nutrir e Manter Conexões \\
\hline Humanista & Conhecimento Preciso e Atualizado \\
\hline \multirow{2}{*}{ Cognitivista } & Nenhum princípio \\
& Diversidade de Opiniões \\
\hline Sociocultural & Capacidade de Saber Mais \\
& Necessidade de Nutrir e Manter Conexões \\
\hline
\end{tabular}

Fonte: elaborado pelos autores

Pela percepção dos alunos os hábitos comportamentalistas são os que mais detêm efeito sobre os princípios, pois exercem o mesmo em todos. Em segundo lugar está a percepção das abordagens cognitivistas, nestas são explorados três dos quatro princípios estudados, apenas o conhecimento preciso e atualizado não foi comprovado. Já a abordagem sociocultural é a segunda mais limitada na percepção dos alunos, pois só detém efeito em dois princípios.

Estes resultados sugerem que os professores que executam as habilidades congnitivistas são os que mais aumentam as possibilidades de explorar as mídias sociais em sala de aula. Em ressalva, essa pode ser a percepção das habilidades dos professores que mais são presentes nas Instituições pesquisadas. Nesse contexto, as percepções das abordagens metodológicas detêm efeitos sobre os princípios do conectivismo elencados por Siemens (2005). No próximo bloco serão abordadas as considerações finais. 


\section{CONSIDERAÇÕES FINAIS}

O presente estudo objetivou analisar a influência das abordagens metodológicas nas mídias sociais à luz dos princípios do conectivismo descrito por Siemens (2005). Dessa forma, foram elencados desafios compostos por limitações, pelas concepções pedagógicas e pela utilização das mídias sociais, com o objetivo de se identificar quais detêm efeito sobre as abordagens metodológicas. A percepção dos alunos sobre as abordagens possibilitou identificar aquelas que mais elevam a percepção sobre os princípios do conectivismo no ambiente acadêmico.

A importância de se analisar a percepção dos alunos caracteriza-se pelo fato destes serem os agentes principais no processo de ensino (MIZUKAMI, 1986). Ainda que os alunos não detenham os conhecimentos das abordagens metodológicas, são hábeis a indicar a sua percepção sobre os hábitos dos professores com os quais conviveram, como também para demonstrar a sua concepção referente a esses hábitos.

Os resultados sugerem que as percepções dos acadêmicos sobre algumas práticas metodológicas dos professores influenciam diferentes atributos do uso das mídias sociais no processo de ensino. Por exemplo, a abordagem comportamentalista é a que permite aos professores explorar mais as mídias sociais para fins acadêmicos. Em segundo, a abordagem cognitivista, porém esta não detém o efeito sobre o foco do conhecimento preciso e atualizado. Entretanto, no que concerne à abordagem sociocultural, apenas dois princípios são alavancados. Não obstante, as abordagens tradicional e humanista não permitem aos professores aumentar o interesse dos acadêmicos perante a utilização das mídias sociais no processo de ensino.

A principal contribuição desse artigo se dá no fato de que, na percepção dos alunos as mídias sociais podem ser favorecidas de acordo com as abordagens metodológicas. Salientase também que, de acordo com essas abordagens elencadas, os professores podem procurar direcionar suas práticas para as abordagens comportamentalistas quando tiverem o intuito de estimular as mídias sociais no processo de ensino.

Como limitação têm-se apenas as percepções dos alunos sobre as abordagens metodológicas propostas por Mizukami (1986), além do fato de que para adoção de tais abordagens, os professores devem ter ao menos o conhecimento das mesmas. Destaca-se, que na área de Contabilidade, muitos professores não detêm conhecimentos voltados para a docência e o fazem por meio do isomorfismo. 
Sugere-se, para pesquisas futuras, abordar os focos dos professores sobre as mídias sociais no processo de ensino, pois essa percepção poderá gerar algum tipo de contribuição, comparando-se com os resultados encontrados nessa pesquisa. Faz-se interessante também pensar em uma comparação entre instituições públicas e privadas, no intuito de se identificar diferenças no uso das mídias sociais com a finalidade de ensino entre tais.

\section{REFERÊNCIAS}

AGARWAL, S.; MITAL, M. An exploratory study of Indian university students' use of social networking web sites: Implications for the workplace. Business Communication

Quarterly, v. 72, n. 1, p. 105-110, 2009.

AJJAN, H.; HARTSHORNE, R. Investigating faculty decisions to adopt Web 2.0 technologies: Theory and empirical tests. The Internet and Higher Education, v. 11, n. 2, p. 71-80, 2008.

BARCZYK, C. C.; DUNCAN, D. G. Social networking media as a tool for teaching business administration courses. International Journal of Humanities and Social Science, v. 1, n.17, p. 267-276, 2011.

BARBOSA, J. S. D.; FERREIRA, S. L. Mídias sociais, educação e formação docente. Interfaces Científicas-Educação, v. 1, n. 2, p. 81-90, 2013.

BARRON, B. Interest and self-sustained learning as catalysts of development: A learning ecology perspective. Human Development, v. 49, n. 4, p. 193-224, 2006.

BARTOW, S. M Teaching with social media: Disrupting present day public education. Educational Studies, v. 50, n. 1, p. 36-64, 2014.

BOSMAN, L.; ZAGENCZYK, T. Revitalize your teaching: Creative approaches to applying social media in the classroom. In: Social media tools and platforms in learning environments. Springer Berlin Heidelberg, p. 3-15, 2011.

BUZZARD, C. et al. The use of digital technologies in the classroom: A teaching and learning perspective. Journal of Marketing Education, 2011.

CAO, Y.; AJJAN, H.; HONG, P. Using social media applications for educational outcomes in college teaching: A structural equation analysis. British Journal of Educational Technology, v. 44, n. 4, p. 581-593, 2013.

CARLSON, D. 2007 AESA Presidential Address Conflict of the Faculties: Democratic Progressivism in the Age of "No Child Left Behind". Educational Studies, v. 43, n. 2, p. 94113, 2008.

CORRAR, L. J.; PAULO, E.; DIAS FILHO, J. M. Análise multivariada: para os cursos de administração, ciências contábeis e economia. São Paulo: Atlas, 2007. 
CRUZ, N. V. S. O que me ensina a aprender? Uma análise do uso da tecnologia da informação e comunicação no processo de ensino-aprendizagem em contabilidade no Estado da Bahia. 2015. Dissertação de Mestrado em Ciências Contábeis, Programa de Pós-graduação em Contabilidade da Faculdade de Ciências Contábeis da Universidade Federal da Bahia, Salvador, 2015.

DIAS, C.; COUTO, O. F. D. As redes sociais na divulgação e formação do sujeito do conhecimento: compartilhamento e produção através da circulação de ideias. Linguagem em (Dis) curso, v. 11, n. 3, p. 631-648, 2011.

DOTTA, S. Uso de uma mídia social como ambiente virtual de aprendizagem. In: Brazilian Symposium on Computers in Education (Simpósio Brasileiro de Informática na Educação-SBIE) v. 1, n. 1, 2011.

FACINELLI, S. What the heck is social media? Franchising World, v. 41. n. 7, p. 40-42, 2009.

GEE, J. P. Situated language and learning: A critique of traditional schooling. Literacies: New York, 2004.

GREENHOW, C. Online social networks and learning. On the Horizon, v. 19, n. 1, p. 4-12, 2011.

HAIR JR., J. F. et al. Fundamentos de métodos de pesquisa em administração. Bookman: Porto Alegre, 2005.

HARRIS, A. L.; REA, A. Web 2.0 and virtual world technologies: A growing impact on IS education. Journal of Information Systems Education, v. 20, n. 2, p. 137-144, 2009.

KELLNER, D. Technological transformation, multiple literacies, and the re-visioning of education. E-Learning, v. 1, n.1, 2004.

LIBBY, R.; BLOOMFIELD, R.; NELSON, M. W. Experimental research in financial accounting. Accounting, Organizations and Society, v. 27, n. 8, p. 775-810, 2002.

LIKER, J. K.; SINDI, A. A. User acceptance of expert systems: a test of the theory of reasoned action. Journal of Engineering and Technology Management, v. 14, n. 2, p. 147173, 1997.

LUKE, C. Cyberpedagogy. In: WEISS, J., et al. (Eds.) The international handbook of virtual learning environments. 14. ed. Dordrecht: Springer, p. 269-277, 2006.

MALHOTRA, N. K. Pesquisa de marketing: uma orientação aplicada. 4. ed. Porto Alegre: Bookman, 2006.

MIZUKAMI, M. G. N. Ensino: as abordagens do processo. Editora Pedagógica e Universitária, 1986.

PARRY, M. Most college professors use social media. Chronicle of Higher Education, v. 56, p. 36, 2010.

SIEMENS, G. Connectivism: A learning theory for the digital age. Instructional Technology and Distance Education, v. 2, n. 1, p. 3-10, 2005. 